\title{
SANTIAGUISTAS Y TERESIANOS, SEDENTARIOS Y NÓMADAS, CON PROPAGANDA FIDE Y CHINA AL FONDO*
}

\author{
POR \\ JosÉ ANDRÉS-GALLEGO \\ Centro de Ciencias Humanas y Sociales, CSIC, Madrid
}

En otro lugar ${ }^{1}$, al referirme al problema suscitado por los símbolos religiosos en varios países de Europa al comenzar el siglo XXI (velo que tapa medio rostro femenino, «burka» que lo logra ocultar completamente, visibilidad de mezquitas en 2009 en Suiza, «caso Lautsi» en Italia en 2011), recordé una circunstancia propiamente historiográfica. Hace cosa de un año, una historiadora italiana me invitó a tomar parte en la elaboración de un libro donde se examinara la eficacia que ha tenido, en el mundo mediterráneo, la concreta filosofía de la historia que se configuró en el mundo germano a finales del siglo XVIII y principios del siglo XIX, de acuerdo con la cual es la cultura compartida la que hace realidad una nación; nación que, si se asienta y permanece en un espacio concreto que permita la convivencia de sus miembros, es, propiamente, un «pueblo», que, por naturaleza, propende a convertirse en estado soberano. Para ellos -digo los promotores del volumen-, la ecuación definitoria de la comunidad política es, por tanto, la que hace «cultura» igual a «nación» que, si se suma un territorio, es igual a «pueblo»y, por ello, a «estado soberano» (o sea: [cultu$\mathrm{ra}=$ nación $]+$ espacio $=$ pueblo $=$ estado soberano) .

Si se acepta que, en los casos que comentamos, la religión cristiana se reduce -en parte-a la visión de unas raíces culturales, podemos concluir que, en aquella

\footnotetext{
* Estas páginas se enmarcan en el proyecto Imperios, Naciones y Ciudadanos en Asia y el Pacífico: (HAR2009-14099-CO2-02), que se desarrolla en el Consejo Superior de Investigaciones Científicas.

Preprint a aparecer en el Anuario de derecho eclesiástico del estado correspondiente a 2012.

1 «Notas históricas sobre el problema de los símbolos religiosos»: Anuario de Derecho eclesiástico del Estado, en prensa.
} 
ecuación, podría sustituirse el concepto «cultura» por el concepto «religión»y, en este caso, resultaría que religión es igual a «nación» y, si se aglutina en un espacio, igual a «pueblo» e igual a «estado soberano». En el libro de que hablo, me correspondía hablar sobre España, país del que diríamos -sobre todo, entre los españoles-que es, por antonomasia, aquel que tiene «las» raíces cristianas. No podemos imaginarnos que es lo mismo que aseguran, de sí, los suizos, como ocurre con los franceses y con la mayoría de los occidentales. Pero no hay que preocuparse; los suizos y demás piensan también que ese carácter es suyo únicamente y, si les llega la noticia de que alguien lo comparte, lo llaman de otro modo (distinto de «religión»o «cristianismo», sino «intolerancia» y demás).

Es cierto, sin embargo, que España - con Hungría- es «religiosa» de una manera concreta y no poco singular: su «identidad» está ligada íntimamente a la defensa de la religión cristiana frente al Islam durante siglos. ${ }^{2}$ Como saben fue el valladar frente al Islam entre el VIII y el XVII. Croacia y Bosnia lo son de otra manera $-\mathrm{y}$ paradójica-: como un enfrentamiento a tres bandas. Polonia también. Sólo que las tres bandas son cristianas (las suyas católicas, las prusianas protestantes y las rusas ortodoxas). En cambio, en Hungría y España, fue el Islam.

Por fin, en otros casos (Suiza entre ellos), las raíces correspondientes datan de situaciones posteriores, en concreto de la reforma protestante del siglo XVI, que es lo más común en Europa. En algún caso, es necesario retrasarse al XV (como sucede con los checos en torno a Hus). Pero, en todas partes, fue decisivo aquel planteamiento de finales del XVIII y comienzos del siglo XIX, en el mundo germano, para que cada cual replantease -e incluso ahormase- su propia historia.

$$
* * *
$$

En último término, lo que hunde las raíces en fechas tan distintas pero se conceptúa de manera homogénea en el Ochocientos es lo que podemos llamar «nacionalización de las creencias», por más que tanto monte hablar de «confesionalización» de las naciones.

En ese caso, sí, puede afirmarse que, con la unión dinástica de los Reyes Católicos y la incorporación de Navarra a la corona de Castilla en 1515, España se dibuja como una de las primeras «naciones confesionales.

El contrapunto protestante no tardaría treinta años -ni una generación siquiera- en surgir, en la Inglaterra de Enrique VIII y, enseguida, en otros países. La propia imposición del principio cuius regio eius religio propiciaría esa «confesionalización».

\footnotetext{
${ }^{2}$ Remito a Berend, Nora. 2003. «Défense de la Chrétienté et naissance d'une identité: Hongrie, Pologne et Péninsule ibérique au Moyen Âge»: Annales HSS. 5: 1.009-1.027.
}

Hispania Sacra, LXIV

130, julio-diciembre 2012, 739-761, ISSN: 0018-215X, doi: 10.3989/hs.2012.022 
Antes de entrar en lo que eso supuso en las comunidades políticas donde se mantuvo, a pesar de todo, el pluralismo religioso, debo indicar un par de cosas. La primera es que ese principio (cuius regio eius religio) fue importante - precisamente- en los países donde se había impuesto la Reforma, pero que eso no implica deducir que no tuvo importancia -o que no cambiara las cosas- en los países donde se daba ya la unanimidad.

Pocos lo ilustran de manera tan singular y clara como España. Me refiero al debate que se suscitó en esos días, cuando algunos pensaron y acabaron por defender públicamente que se declarase a santa Teresa -recién beatificada- patrona de España misma; asunto al que Erin Kathleen Rowe ha consagrado un libro que merece la pena y que paso a glosar, ${ }^{3}$ claro es que sin ceñirme a una mera descripción de lo que contiene.

Como ya era patrón Santiago y no era cosa de provocar sus iras -digo las de los santiaguistas-, los teresianos no dudaron en afirmar que, por supuesto, la santa de Avila admitía quedarse en copatrona con tal que se prestara a esa misma rebaja el señor don Santiago. Y podría decirse que ardió Troya, si no fuera porque el debate quedó en asunto de palabras.

Lo singular es que la discusión se apoyara, en gran parte, en argumentos propiamente «nacionales» y no en la diferencia que pudiera terciar entre ambos candidatos. Los teresianos, ciertamente, valoraban la representación -que ofrecía la santa- de la respuesta que habían dado los católicos (entiéndase la Iglesia entera) a la Reforma protestante. Era, en ese sentido, un testimonio espléndido de la respuesta hispana a lo que, en esos días -los del siglo XVII- preocupaba más a los europeos que continuaban engolfados en las guerras de religión.

Como es sabido, los Austrias españoles seguían esforzándose en conseguir la unidad de la cristiandad y ello a pesar de lo que se concertó en Westfalia en 1648. Santa Teresa no deslucía, por tanto, el esfuerzo tremendo que desangraba el país (sobre todo a las gentes de los reinos europeos de la corona de Castilla, que eran sobre quienes pesaba, ante todo, el gigantesco esfuerzo que exigía levantar un ejército y otro ejército y, luego, otro más; y eso durante más -bastante más- de siglo y medio).

Y era eso mismo, sin embargo, lo que dolía más a los santiaguistas que valoraban grandemente el carácter de matamoros del apóstol y no veían en Teresa una energía semejante (que, en puridad, no podía descartarse en las mujeres, menos aún después del episodio de la monja alférez, Catalina de Erauso; un episodio del que ya circulaba su autobiografía en aquellos días, los de 1625 en

\footnotetext{
${ }^{3}$ Rowe, Erin Kathleen. 2011. Saint and nation: Santiago, Teresa de Avila, and plural identities in early modern Spain, University Park, Penn., The Pennsylvania State University Press: 264 págs.
} 
concreto ${ }^{4}$ ). Para ellos, el patronazgo de Teresa -aunque fuera copatrocinio- no dejaba de parecer una contradicción, que era la que latía en el gravísimo hecho de proponer a una mujer y pacífica monja de clausura - por aguerrida que fuese o pareciese- a un pueblo que se había perfilado como tal en las guerras contra el infiel, y eso en los últimos nueve siglos, sin solución de continuidad: contra los moros durante más de setecientos años, que, sin cesura de ningún género, continuaban en la forma del corso que asolaba el Mediterráneo en pleno siglo XVII.

En 1492, la cosa había empalmado además, al otro lado del Atlántico, con los enfrentamientos belicosos a otro tipo de infieles, y eso para volver -muy pronto, entrado el XVI- a las tierras de Europa infestadas por la herejía protestante.

Para los valedores de Santiago, en definitiva, el patronazgo de Santa Teresa podía invitar al afeminamiento o, como poco, interpretarse de esa forma (dentro y fuera de España).

Para que se mida bien el alcance de aquel debate $-\mathrm{y}$ no nos conformemos con saber a qué altura llegó-, advirtamos que su bajura alcanzó a la propia beatificación y que unos rehuían llamar «beata» a la santa $-\mathrm{y}$ le daban el nombre de «doncella»-, precisamente porque otros recordaban que, en el castellano de entonces, por «beata» podía entenderse de forma diferente, según cuál fuese la acepción, y que no eran tan dignas -las demás acepciones- como la que terciaba en el debate (Rowe: 59).

La mayor altura de aquella discusión se alcanzaría acaso en su aspecto de discusión entre lo «viejo» y lo «moderno» (Rowe: 64), que se podría entender como faceta hispana del clásico debate de aquel tiempo entre «antiguos» y «modernos», sobre el que ahora contamos, en nuestra lengua, con el estudio -centrado en Francia- de Marc Fumaroli. ${ }^{5}$ Pero no hay que olvidar que en las antípodas -concretamente en China y Filipinas- los propios españoles estaban engolfados en un debate hermano y, sin embargo, muy distinto: el de los ritos chinos; un tema demasiado ignorado en la historiografía española -pese al protagonismo de una de las partes en liza, que fue la hispana justamente- pese a contribuciones como la de Eva María Saint-Clair sobre su tardía influencia -la de ese asunto- en la extinción de la Compañía de Jesús, ya en 1774;6 atendido

\footnotetext{
${ }^{4}$ Se puede leer en bib.cervantesvirtual.com y hay varias ediciones. Vid., además, la edición y estudio de Rubio Merino, Pedro. 1995. La monja alférez doña Catalina de Erauso: Dos manuscritos inéditos de su autobiografía conservados en el Archivo de la Santa Iglesia Catedral de Sevilla, Sevilla, Cabildo Metropolitano de la Catedral: 171 págs.

${ }^{5}$ Fumaroli, Marc. 2008. Las abejas y las arañas: La querella de los antiguos y los modernos, Barcelona, Acantilado: 276 págs.

${ }^{6}$ Saint-Clair, Eva María. 2000. Dios y Belial en un mismo altar: Los ritos chinos y malabares en la extinción de la Compañía de Jesús, San Vicente de Raspeig, Universidad de Alicante: 294 págs.
}

Hispania Sacra, LXIV

130, julio-diciembre 2012, 739-761, ISSN: 0018-215X, doi: 10.3989/hs.2012.022 
en cambio en Italia por el protagonismo que le cupo al jesuita Mateo Ricci, el centenario de cuyo dies natalis se cumplió en 2010 y dio lugar a un importante elenco bibliográfico que ha pasado un tanto desapercibido en España, pese a lo que le toca, y del que cabe ver información en www.pmatteoricci.it.

$$
* * *
$$

Puede parecer sorprendente que relacionemos lo uno con lo otro; pero ya verán si hay o no relación. $\mathrm{Al}$ cabo, en ambos casos, se trataba de elegir entre lo antiguo y lo moderno. Ahora recuerden, no obstante, que, en el debate de que hablamos -un debate europeo sobre todo-, lo «antiguo» era lo propio de la Grecia y la Roma clásicas; no era, por tanto, una calificación peyorativa; con el «renacimiento» de la cultura antigua, había reverdecido la conciencia de que, entre aquellos clásicos griegos y romanos, se había llegado a definir el canon de la belleza y, por lo tanto, lo que se discutía era si procedía ceñirse a ese canon -tesis que sostenían los «antiguos»- o si era lícito innovar, claro está que fielmente, conforme al propio canon (y era eso lo que se consideraba «moderno», con latinismo muy tardío por cierto).

Dirán ustedes -con razón- que, en puridad, al pleito sobre los ritos chinos -como, en rigor, al de Santa Teresa y Santiago- no le cuadraba propiamente ni el adjetivo «clásico» ni tampoco el de «antiguo». Mantener a Santiago como patrono único de España o hacerle acompañarse de Teresa era más bien asunto de «identidad». Pero, por aquellas calendas, no solía emplearse esa palabra si no venía a cuento de forma ineludible.

Y lo mismo podía decirse del debate sobre los ritos chinos; también era cuestión de «identidad». De una distinta identidad en cada caso -eso es cierto-, pero arraigadas ambas en el «genio» español (entonces, para hablar de la «identidad», se prefería esa palabra, «genio») y era el genio español el que se consideraba encarnado en el Matamoros y, en la China, en la predicación del cristianismo, digamos, a pelo. ${ }^{7}$

No se puede decir que esto último, al menos, sí fuera cosa «antigua», dado que es lo que hicieron los doce apóstoles primeros cuando se les asignó esa misión. En los siglos siguientes -todos los que mediaron hasta llegar al año 1500 y su entorno-, habían sucedido muchas cosas y se cristianó a las gentes que habitaban Europa de formas muy distintas a las de aquellos Doce. Daban fe de ello los judíos (y muchos otros). Intenté explicarlo en Italia, precisamente, en un convegno que, por lo demás, fue notable..$^{8}$

\footnotetext{
${ }^{7}$ Sigue en pie el estudio de Sun Su Ming, Julia. 1981, El padre Domingo Fernández Navarrete y el problema de los ritos chinos, Madrid, Universidad Complutense de Madrid: 514 págs.

${ }^{8}$ Andrés-Gallego José. 2007. «La Spagna medievale, tra Reconquista, espulsione». Las ponencias se publicaron. 2007, La Nuova Europa: Rivista Internazionale di Cltura, 331/1 7).
} 
De hecho, la cristianización de América no pudo plantearse como la del Islam. Si acaso, el precedente más cercano anduvo con la de las Canarias, cuya evangelización se adelantó, además, al dominio político. Los guanches recibieron libremente el bautismo antes de que llegasen otros europeos con intenciones muy distintas.

Pero la magnitud del continente hallado al otro lado del Atlántico mostró tal cantidad de lenguas y culturas, que obligó a reconsiderar todo lo que se había dado por seguro.

Y uno de los aspectos que quedó claro en poco tiempo es que la evangelización podía medrar allí donde los «indios» fueran sedentarios. La catequesis requería muchas horas de diálogo y sosiego y, como, de otra parte, los propios misioneros eran personas sedentarias y no podían vivir de otra manera -si querían persistir en su «religión» (en el sentido propio de este término, o sea en su instituto de perfección)-, acabaron por concluir que, primero de todo, había que «reducir a pueblo»-como entonces se dijo- a aquellos a quienes se pretendiera cristianar. Fue una de las conclusiones más claras de la pedagogía misionera que expresó el jesuita Acosta, sobre el que sigue trabajando -por fortuna- Fermín del Pino y lo ha hecho ya con la mirada puesta, precisamente, en su proyección ultramericana, o sea sobre Oriente ${ }^{9}$ (además de dar a la luz la necesaria edición crítica de la Historia Natural y moral de las Indias ${ }^{10}$ ).

$$
* * *
$$

El caso es que reducirlos a pueblo no consistía tan sólo en conseguir que construyeran casas y abandonaran las «tolderías» en que solían vivir los indígenas nómadas, sino que requería todo un cambio de vida. Los nómadas tendían a ajustar la suya al desplazamiento de las manadas de animales de que se alimentaban; no eran -salvo excepciones- agricultores, sino «recolectores» de los frutos silvestres y, por tanto, no sólo había que enseñarles a edificar, sino a labrar, cultivar y cosechar; cosa que requería tierras en propiedad común o privada (o las dos cosas) y, por lo mismo, en unas normas propiamente jurídicas y alguien que las dictara y que las hiciese cumplir. En fin, tenían que aprender a gobernarse y bastarse por sí mismos.

La bibliografía sobre las «reducciones» americanas ha tendido a ceñirse exclusivamente a las famosas guaraníes. Hubo muchas más (y algunas, con mucho menor éxito que las mentadas). Pero aquellas dejaron un ejemplo de riqueza inusual. Carlos A. Page ha editado siete hermosas biografías de otros tantos jesuitas que anduvieron precisamente por la provincia del Paraguay y

\footnotetext{
${ }_{9}$ Pino, Fermín del. 1985. «El misionero español José de Acosta y la evangelización de las Indias Orientales», Missionalia hispanica, XLII/2: 275-297.

10 2008. Madrid, Consejo Superior de Investigaciones Científicas: 330 págs.
}

Hispania Sacra, LXIV

130, julio-diciembre 2012, 739-761, ISSN: 0018-215X, doi: 10.3989/hs.2012.022 
acierta a unir, en ese libro, los aspectos estrictamente misionales con los arquitectónicos (gracias a su condición doble de historiador y de arquitecto. ${ }^{11}$ ).

Es significativo -y bello, a mi entender- que se dijera que, toda esa labor, se resumía en «poner en policía» a aquellas gentes, y eso porque era ahí dónde asomaba claramente la conciencia del clasicismo del intento. «Reducir a pueblo» a unas gentes que eran nómadas hasta entonces y «ponerlas en policía» era una consecuencia primordial y consciente de aquella herencia griega según la cual un varón puede ser libre únicamente en una «polis». La diferencia (capital) es que, en la Grecia clásica, eso lo conseguían muy pocos -y ninguna mujer-, en tanto que en los nuevos «pueblos de indios» todos podían ser libres realmente. Sucedía, claro es, que la idea de libertad había cambiado enormemente; la libertad real, en la polis griega, sólo la conseguía aquél que contaba con patrimonio suficiente para que otros trabajasen por él y, de esa forma, él mismo se pudiera consagrar a razonar con plena libertad -sin ninguna necesidad que atender- sobre el modo mejor de gobernarse (o sea de gobernar a los demás y de gobernarse a sí mismo). En el caso de los cristianos, sin embargo, la libertad que implicaba el bautismo trascendía todo eso; los liberaba de la muerte.

Ya sé que mucho de eso quedaba, a veces, en aparente juego de palabras y que, además y sobre todo, servía en ocasiones para justificar un orden político casi tan poco liberal como era el de la mismísima Atenas. Pero creían que era así y eso es lo que interesa poner ahora de relieve.

En la práctica eso supuso la mayor extensión que cabía pensar no sólo para la fe en Cristo Jesús, sino para la propia cultura de la Europa cristiana occidental, y ello hasta el punto de que ambas cosas quedaron vinculadas de tal suerte, que, más que fundirse, se confundieron totalmente como una sola realidad.

¿Quiere decir todo eso que la evangelización de América no conllevó el intento de «hispanizarla»? Ya lo creo que lo supuso. Lo que sucede es que, en el siglo XVI, la cultura española se había empapado de «Renacimiento» de las formas clásicas en medida que sólo superaron quizá los italianos. Ni franceses, ni británicos ni germanos lograron o dejaron que prendiera el clasicismo como prendió en la enorme monarquía, incluidos Portugal y los Países Bajos, además de los propios reinos de Indias, durante el siglo XVI. No es el menor botón de muestra la «relatinización» que ganó la lengua de Castilla y, de rechazo, los demás romances hispanos que consiguieron sobrevivir a la pujanza de la lengua del rey de medio mundo. La reedición del Nuevo diccionario etimológico latínespañol y de las voces derivadas, de Santiago Segura, sigue levantando acta del interés y del alcance de aquel fenómeno cultural. ${ }^{12}$

\footnotetext{
${ }^{11}$ Page, Carlos A. 2011. Jesuitas en las reducciones y colegios de la antigua provincia de Paraguay, Buenos Aires, Editorial SB: 250 págs.

12 2006. $3^{\mathrm{a}}$ ed., Bilbao, Universidad de Deusto: 1.251 págs.
} 
Y, por lo mismo, sólo intentó Felipe II (y, ya en el siglo XVIII, Carlos III) conseguir que la lengua de Castilla se hablara en todas partes. Los delegados del monarca y, sobretodo, los misioneros no dudaron en mantener el viejísimo criterio de predicar el evangelio en la lengua nativa de quien les escuchaba.

$$
* * *
$$

El principal problema -o uno de los notables, por lo menos- es que, en otros países, no se veía así. En la propia curia romana, se daba por supuesto que los misioneros hispanos actuaban como portavoces de un rey que defendía sus propios intereses; intereses que no tenían que ver con los de la curia romana, y no cejaron hasta que consiguieron promover misiones ad gentes que dependieran de ellos mismos o de quienes dependían de ellos. Y la experiencia -por fallida que fuere- de Mateo Ricci no fue sino un hermoso precedente de la decisión de crear Propaganda Fide en la propia Roma (1622).

A China habían llegado los misioneros españoles que pasaron de Filipinas mediado el siglo XVI y consiguieron que les dejaran asentarse en el continente y predicar. E, igual que hacían en América, lo primero que procuraron fue estudiar la cultura china $-\mathrm{y}$, por tanto, la lengua- para entenderla y ver el modo mejor de cristianarla, sobre la base, sin embargo, de que el cristianismo es lo que es -la transmisión más fiel posible de una tradición muy concreta (la de los Doce)- y que, por tanto, lo que procede es expresarla con las palabras de la cultura respectiva que permitan la comprensión, digamos, conceptual.

En América, ya había suficiente experiencia de culturas indígenas que carecían de expresiones para algunos de esos conceptos y, en ese caso, no había más remedio que introducirlos ex novo.

Esa experiencia de los primeros misioneros hispanos -y la acumulada durante siglos por muy diversos viajeros que habían llegado a China desde Europa o habían conseguido, en países cercanos, la información que deseaban- fue lo que recogió Mateo Ricci y le indujo a probar con una táctica-o pedagogía- distinta de la de aquéllos (incluida la de la mayoría de los sus propios hermanos de orden, los jesuitas hispanos, fieles por el contrario a la propuesta que teorizó Acosta).

El primer problema fundamental radicaba en que, en chino, faltaban formas léxicas que sirvieran para expresar -de aquella forma cabal y completa-cuanto había que decirles para que comprendiesen aquél mínimo imprescindible (para empezar, la propia idea de «Dios»13) y Ricci y sus compañeros optaron por la

${ }^{13}$ Ha vuelto sobre ello Xiaoyang, Zhao. 2011. «In the name of God: Translation and transformation of Chinese culture, foreign religion, and the reproduction of «Tianzhu» and «Shangdi», Journal of Modern Chinese History, IV/2:163-178. 
elaboración de un cristianismo fragmentario, que permitiera a aquellas gentes aceptar lo que se les decía sin que les repugnara no sólo porque su lengua careciera de palabras para expresar esos conceptos, sino porque -las tuviera o nosuponían verdaderas rupturas con sus propios supuestos culturales.

Los misioneros españoles se echaron las manos a la cabeza; el asunto acabó por llegar a Roma y el debate sobre los «ritos chinos» se prolongó hasta mediar el siglo XVIII..$^{14}$

En realidad, Matteo Ricci habían llegado a China por la vía de la jurisdicción del rey de Portugal y, además, en la época en que formaba parte el propio Portugal de la Corona de Castilla. No tendría por qué haberse planteado, por tanto -la cuestión de los ritos chinos-, como asunto político. Pero acabó por enlazar.

Tampoco cabe deducir, sin más, que fue un enfrentamiento entre órdenes religiosas; la división surgió en el seno de la propia Compañía de Jesús.

No procede, por fin, entenderlo como un enfrentamiento entre italianos y españoles. No faltarían españoles que apostaran por la pedagogía de Matteo Ricci.

Pero, con el paso del tiempo, la cosa se revistió de esa manera y terminó por presentarse como una alternativa misional que oponía la inspiración del Rey España a la Sede Apostólica Romana, el poder o la autoridad del obispo de Roma a la de los monarcas de Castilla, el modo itálico al modo español de hacer las cosas y, claro, a los jesuitas frente a todos los demás.

Replanteamientos como ése, no es difícil hallarlos en la historia. Con el tiempo, las razones originales se afirman con argumentos nuevos que, con frecuencia, definen los perfiles de las posturas respectivas con una nitidez de la que carecían. La disputa sobre los «ritos chinos»-que fue como el asunto pasó a la historia- se prolongó también en la propia Roma y dio lugar a diversas intervenciones de otros tantos sucesores de Pedro, quienes -con mayor o menor empeño- rechazaron e incluso condenaron los ritos en cuestión hasta ratificarlo a mediados del siglo XVIII, ahora en términos tales que quedó expresamente prohibido seguir con el debate.

Y, aun así, todavía se discutía sobre ellos muy pocos meses antes de que Clemente XIV optase por la disolución de la Compañía de Jesús, cierto que por otros motivos, en 1773.

El debate había cumplido, para entonces, bastante más de siglo y medio.

\footnotetext{
${ }^{14}$ No es posible entrar ahora en la amplia bibliografía que tiene el asunto. Permítaseme -por lo singular del punto de vista (que relaciona cultura japonesa, cultura china y evangelización de una y de otra)- remitir solamente al conjunto de estudios reunidos por M. Antoni, M. y Ǘçerler J. 2009. Christianity and cultures: Japan \& China in comparison 1543-1644 Roma, Institutum Historicum Societatis Iesu: XLVI + 410 págs.
} 
Y -entonces sí- las posturas de los -digamos- herederos de los contendientes de siglo y medio atrás se habían perfilado de otro modo. No es que contaran con nuevos argumentos sobre aquella cuestión; lo que ocurría es que tenían otros motivos para enfrentarse y algunos de ellos no rehuyeron el viejo asunto de los ritos cuando pudo servirles para apoyar su respectiva posición.

En 1773, el rey de España no valoraba tanto su propia sangre austriaca como a sus ancestros franceses -los Borbón-; hablaba del monarca francés como de «su primo» y lo consideraba cabeza del linaje a que él mismo pertenecía; había hecho traducir y publicar las obras de Bossuet y dejaba que lo considerasen no ya «Patrono» de las iglesias de la Monarquía, sino -explícitamente- «Vicevicario de Cristo en la tierra», y no creía, desde luego, que su poder naciera de un pacto que habría dado origen a la propia monarquía -como se había argüido en la teología hispana del Siglo de Oro-, sino que su autoridad procedía de Dios directamente y, por lo tanto, sólo a Dios tendría que rendir cuentas.

Más una circunstancia principal: los teólogos que, en el siglo XVI, hablaban de ese acto originario constitutivo de la monarquía castellana y -con mayor razón- aragonesa habían sido primeramente dominicos y, luego, jesuitas, sin que hicieran ascos a su postura agustinos y franciscanos; otros -como Martín de Azpilcueta y Diego de Covarrubias- eran clérigos seculares en principio. En 1773, en cambio, hacía más de un siglo que los jesuitas se habían convertido en el baluarte de la autoridad pontificia y el principal poder romano, y eso de forma tal que la propia doctrina del pacto y la antiquísima justificación del tiranicidio se presentaban -erróneamente- como doctrinas definitorias de los jesuitas. Que eran, en consecuencia, el principal enemigo a batir.

Mientras tanto, en la propia Roma en 1621, se había constituido un organismo de Propaganda Fide, desde el que se intentaba encauzar el esfuerzo de recristianización de la Europa protestante (y hasta de las iglesias ortodoxas), además de las misiones ad gentes. El primer rubro de su quehacer -el de recuperar el centro y el este de Europa para la Iglesia- dio frutos relevantes -quizá los principales- durante el siglo XVII, por más que no olvidasen la tarea misional. Es interesante advertir que los reyes de España habían evitado que se multiplicaran las órdenes religiosas en los reinos de Indias y que, al final, se habían circunscrito en gran medida a dominicos, jesuitas, franciscanos y agustinos de diversa obediencia y que fue Propaganda Fide el cauce que permitió que los religiosos de otras órdenes -como los capuchinos-, incluidos los españoles, pudieran misionar en América ${ }^{15}$.

\footnotetext{
15 Véase al respecto el libro de Borges, Pedro. 1992. Religiosos en Hispanoamérica, Madrid, Editorial Mapfre: 340 págs., sobre todo desde la pág. 136.
} 
Pero el organismo romano no tardó en verse envuelto en el replanteamiento eclesiológico y político que hemos visto y se convirtió de ese modo en instrumento que podía servir de contrapeso para la injerencia de los monarcas españoles y portugueses en los asuntos de gobierno de la Iglesia.

En un proceso que conocemos sólo en parte-gracias especialmente a los estudios de Anthony Pagden-, ${ }^{16}$ ya en el siglo XVIII, la publicística antiespañola que -por anticatólica- medraba en los reinos británicos y en los estados protestantes del continente, terminó por ganar Italia y, con Italia, Roma y las propias esferas eclesiásticas, en las que se acentuó la división que ya existía entre defensores de la autoridad del obispo de Roma y quienes remozaban, en cambio, las posturas regalistas y hasta conciliaristas.

Todo eso es importante -digo- porque contribuyó a que, entre los católicos mismos, se impusiera una interpretación de la evangelización de América que hundía sus raíces en la publicística protestante del siglo XVI y XVII y eso -quizá- puso la ya Congregación Sagrada de Propaganda Fide en situación de convertirse a sí misma en ideología.

Ni más ni menos.

Y es que, en la propia Congregación de Propaganda Fide -en un proceso que conocemos mal (aunque sabemos que se dio)-, acabaría por rehacerse no tan sólo su orientación, sino su propia historia, por más que el cambio no llegara a perfilarse -quizá- sino en el siglo XIX, cuando la independencia política de la América española, la apertura forzada del continente asiático y la aún más brutal del África negra, hicieron no sólo conveniente, sino imprescindible la coordinación de las misiones ad gentes desde la propia Roma y se trocó en tarea principal de Propaganda Fide.

Pero de ese caldo de cultivo surgiría una vulgata de su propia historia que acabaría por presentarla como aquello que no había sido: un organismo constituido y alentado por los sucesores de Pedro para remediar la desorientación de las misiones tuteladas por los reyes de España y Portugal, que habrían confundido, en realidad, su propia causa con la del cristianismo y habrían inducido a los misioneros a desarrollar una catequesis basada en la imposición de la lengua española y, con ella, cuanto pertenecía a la cultura peninsular ibérica.

Por eso mismo, cuando se desató el movimiento independentista americano entrado el siglo XIX, en Roma se llegó a la conclusión de que, probablemente, se perdía la cristiandad americana, que se creía abocada a un cisma, dada la confusión entre cultura española y fe católica. Y se encontraron con que no hubo cisma...; pero no se preguntaron por qué (hablando, claro está) en términos generales.

\footnotetext{
16 Pagden, Anthony. 1991. El imperialismo español y la imaginación política: Estudios sobre teoría social y política europea e hispanoamericana (1513-1830), Madrid, Planeta: 253 págs.
} 
La documentación fundamental sobre ese asunto, la publicó Pedro de Leturia hace años y ahí sigue, como un pilar de primer orden..$^{17}$

$$
* * *
$$

Lo que acabamos de esbozar es, en realidad, un campo enorme y casi virgen en la investigación histórica. Y no avanzaremos ni habrá forma de avanzar siquiera un paso mientras no se abandonen las posturas chauvinistas en todas y cada una de las partes implicadas. Esa historia de la que hablamos y tantas más han pasado por el tamiz deformador de la historiografía romántica (cuyos efectos aún colean) y no han logrado zafarse plenamente de él. Se entenderá lo que quiero decir si propongo una lectura del libro de Barrio Gozalo sobre el sistema beneficial en la España de 1475-1834 en función de los temas que acabo de plantear, y eso a pesar de que, en el libro de Barrio, no se habla de ellos; únicamente se detiene en el Regio Patronato de los Reyes de España como una de las formas de provisión de los beneficios, y eso tan sólo en relación con los de España europea, sin asomarse apenas a los reinos de Indias. Pero ya me dirán si arroja o no luz sobre lo que hablamos.

Es un libro de madurez, más que notable corolario de una vida dedicada a la investigación. Barrio Gozalo ha publicado mucho y bueno acerca de la historia de la Iglesia, sobretodo en España y en los siglos XVI-XVIII. Pero no conozco ninguna obra suya en la que se haya decidido como en esta a trazar una síntesis y subordinar por completo la documentación a la probanza imprescindible de lo que dice. Autor de un amplio elenco de estudios que podemos llamar «documentales» ante todo -eruditos, si se prefiere-, se diría que, al fin, ha tomado la pluma - o el teclado correspondiente- $\mathrm{y}$ ha conseguido una obra que me atrevo a llamar maestra.

El asunto del libro no puede ser más importante; todo el edificio eclesiástico - en España como en el resto de la Iglesia latina- se basaba principalmente en el sistema beneficial perfilado durante siglos, de manera que cuando empieza su relato (1475) no era sólo un sistema perfilado y depurado canónicamente, sino viciado por los siglos hasta el punto de reclamar la urgentísima enmienda que se intentó introducir en el Concilio de Trento (y, según se desprende de esta obra, se introdujo efectivamente, pero no se logró aplicar en la medida deseada).

\footnotetext{
${ }_{17}$ Vid. su obra monumental. Leturia, Pedro de. 1959-1960. Relaciones entre la Santa Sede e Hispanoamérica 1493-1835, prólogo de Cristóbal L. Mendoza, Introducción de Joseph Grisar, Caracas, Sociedad Bolivariana de Venezuela: 3 volúmenes. Además, Leturia, Pedro de y Batllori, Miguel. 1963. La primera misión pontificia a Hispanoamérica, 1823-1825: Relación oficial de Giovanni Muzi, Vaticano, Biblioteca Apostólica Vaticana: XXIV + 722 págs. También, Fúrlong Cárdiff, Guillermo. 1957 La Santa Sede y la emancipación hispanoamericana según las investigaciones y los estudios de Pedro de Leturia, S.J., Buenos Aires, Edic. Theoria: 155 págs.
} 
Que, al terminar el siglo XV, ese fuera un principio fundamental en el derecho de la Iglesia permite comprender de inmediato que la figura beneficial concernía, por tanto, a todas las posibles situaciones canónicas en que se hallara un eclesiástico: desde la arzobispal a la de capellán.

La vinculación de un beneficio - precisamente tal, quiero decir «vinculado», amortizado en definitiva- a todo oficio eclesiástico era el modo de asegurar -como poco- la subsistencia del clérigo que desempeñara las funciones correspondientes, sin necesidad de depender de los feligreses ni de cualquier otra persona jurídica o física. Y hay que decir que esa exigencia se había considerado como un avance capital para la mejor salud de la Iglesia; había acabado -o eso se pretendió- con los clérigos «vagos» (en la acepción cuasi canónica de ese término, que no era despectiva en su origen, aunque llegara a serlo en el uso coloquial). Aquí, «vago» quería decir vacuo, «vacío», desprovisto de funciones concretas y, en consecuencia, forzado a la penuria, a la dependencia de las limosnas y, al cabo, a la limosna.

En Trento, quedó zanjado definitivamente -a lo que parecía- el principio según el cual ningún obispo no podía ordenar a un varón que careciera del patrimonio necesario para sobrevivir. Pero eso no hizo sino aumentar la importancia del beneficio que había de ir -y que iba- anejo a todo oficio.

La cristianización de los hispani se había llevado a cabo de una manera similar - mutatis mutandi- a la del resto de la Europa latina y, para trabar la necesaria organización eclesiástica, se recurrió a las mismas instituciones canónicas que en otras tierras europeas. ${ }^{18}$ Ahora bien, ni en estas ni en España, fue un proceso dirigido desde la sede apostólica romana; los obispos de Roma tenían toda la autoridad, pero carecían de medios para llevar a cabo una aventura semejante; empresa que, además, concernía a todo cristiano según se recordaba continuamente y por doquier. La cristianización fue, por lo tanto, labor lentísima de multitud de gentes que pusieron empeño en ello. Aún en el siglo $X$-a lo que parece (y cierto que por excepción, en lugares recónditos, de difícil acceso)- quedaban algunos españoles y españolas que no habían oído hablar de Jesucristo o, por lo menos, no se habían bautizado.

Y bien, esas características del empuje evangelizador fueron las mismas que hicieron realidad el consiguiente esfuerzo de organización de las nuevas comunidades. Desde obispados a iglesias y curatos de aldea, nacieron con frecuencia a iniciativa de laicos (que eran, en unos casos, reyes o gentes de las llamadas «principales» $y$, en ocasiones -muchas-, personas cuyo carácter «principal» no

18 Naturalmente, con todos los matices que sería necesario advertir. Vid., en ese sentido, varios de los estudios reunidos por Teja, Ramón. 2002. La Hispania del siglo IV: Administración, economía, sociedad, cristianización, Bari, Edipuglia: 284 págs. 
trascendía siquiera el lugar al que afectaba la decisión). Y, en unos y otros casos, el sistema beneficial fue el preferido.

Desde Roma, no obstante, también se intervino en la erección de diócesis y diversas instituciones eclesiásticas y, en consecuencia, una parte notable de la provisión de esos cargos se hacía en la Eterna Ciudad.

En otras muchas, correspondía a un prelado español.

$\mathrm{Y}$, en todos los casos, el fundador o fundadores vinculaban un conjunto de bienes al oficio que deseaban mantener. Lo hacían desde luego con la satisfacción -en general- de la autoridad eclesiástica respectiva -y, necesariamente, con su aquiescencia-, y eso porque la «amortización» de esos bienes en situación de absoluta dependencia de ese oficio concreto aseguraba la permanencia de este último en situación jurídica similar al mayorazgo ( $\mathrm{y}$ a las instituciones parejas que había en gran parte de Europa ${ }^{19}$ ); la persona que ejerciera el oficio y disfrutara el beneficio no tendría jamás la propiedad del uno y el otro, sino el usufructo, y, por lo tanto, cuando muriese, no habría sino que nombrar sucesor.

No es extraño, por eso, que las autoridades eclesiásticas de quienes dependía el oficio creado así admitiesen, en muchos casos, que fueran los fundadores de la institución respectiva -aunque se tratase de laicos- quienes designaran al sucesor. La autoridad eclesiástica se salvaba sin más que atribuir a los patronos la «presentación» (de ahí el «derecho de presentación»).

El problema es que los fundadores de beneficios -fuera grande o pequeña su entidad, y ellos mismos laicos o clérigos- fueron introduciendo condiciones que debía cumplir el candidato y, de esa forma, aseguraron que lo fuese a su gusto.

No puede decirse que eso fuera ya un elemento que distorsionaba la institución. Al contrario, podía considerarse -y solía verse de esta manera- como una forma de vincular aún más a la Iglesia al fundador y sucesores del derecho de presentación y, por tanto, a sus hijos y deudos. Fundar una simple capellanía, en consecuencia, podía ser una forma de asegurar el futuro de un deudo y, también, la manera de asegurar que un miembro de esa familia -o estrechamente relacionado con ella- «sería para la Iglesia», conforme a un giro idiomático que aún sobrevive en castellano.

Y ahí empezaban, claro, las posibilidades de corruptela: no siempre se presentaba al candidato idóneo y, a veces, era una forma alternativa del propio mayorazgo: el heredero o heredera del correspondiente derecho de presentación podía acordar previamente con el posible candidato el compromiso de hacerle partícipe de las rentas.

${ }^{19}$ Algunas enumeré y valoré en Andrés-Gallego, J. 1991. Historia general de la gente poco importante, Madrid, Edit. Gredos: 459 págs. 
Por otro lado, bastaba que el propietario del derecho muriese ab intestato* para que lo heredasen -digo el derecho de presentación- varias personas, y eso hasta el punto de que, si ocurría en más de una ocasión, la presentación requería el acuerdo de una pequeña multitud de herederos que, en ocasiones, ni siquiera se conocían ni vivían en el lugar.

No faltaban los casos, por fin, en que el derecho de presentación pertenecía a todos los vecinos, que llevaban a cabo, en consecuencia, unos verdaderos «comicios» para elegir entre los candidatos.

Esto último no se desconocía en Castilla (Barrio habla, por ejemplo, de Medina del Campo), pero era más frecuente en Galicia, Asturias, las Vascongadas y Navarra y el norte de Aragón. Y, sin duda, daba lugar a notables conflictos que acababan en pleito.

Los poquísimos estudios de casos concretos de los que tenemos noticia y que, por lo que sigue, se hacen ahora imprescindibles, muestran que, en otras ocasiones, era la forma de lograr que se nombrara al eclesiástico más apto para las condiciones concretas del oficio correspondiente. No parece casual que varias de las regiones españolas que acabamos de enumerar fueran bilingües y -en los tiempos de los que hablamos- monolingües en gran medida, y de una lengua ajena al castellano. En esos casos, el dominio del idioma nativo aseguraba una catequesis y una pastoral que -para empezar- se entendiera, aun cuando el eclesiástico elegido no fuese el mejor preparado doctrinalmente.*

Ni que decir tiene que, según cundieron por la Europa católica, del siglo XVI en adelante, los principios y prácticas políticas de carácter absolutista, se vio todo eso como una inoportuna cuando no inaceptable participación de los laicos en el poder que, a su vez, disputaban los príncipes, de un lado, y los obispos de Roma, de otro. No es casual que los intentos de reforma que recoge Barrio Gozalo para el caso de España aumenten en el siglo XVII, pero sean cosa, en realidad, del XVIII y principios del XIX. En muchos casos, la reforma era precisa porque había gran número de beneficios «incongruos» (o sea que carecían de la dotación económica suficiente y obligaban al clérigo beneficiado a buscar complementos o incluso un sustituto). Pero también se deja ver que esos intentos reformistas obedecían a la presunción -netamente ilustrada- de que el mejor educador era el cura secular -frente a los religiosos- y que lo idóneo era conseguir un sistema de promoción justo -en términos administrativos- que diera también seguridad al ganador. Por ese camino -elogioso por tantas razones- se podía ir camino de la conversión de los curas en funcionarios incluso del estado (desde el momento en que se sustituyeran las retas del beneficio por un salario contemplado en los presupuesto generales de la monarquía). Y eso fue lo que se impuso en España en un proceso que culminó con la firma del concordato de 1851 . 
Hasta el siglo XVIII (al menos), la actitud de los obispos de Roma en relación con el derecho de presentación de tal o cual príncipe dependía, en definitiva, de sus relaciones con él y de la valoración que hiciese el pontífice de cada persona. Por una parte, seguían en pie los Estados Pontificios y el poder coactivo de esos príncipes -los ejércitos- no era cuestión a desdeñar por quien era, en definitiva, otro príncipe, solo que de la Iglesia. El derecho de patronato a favor de los príncipes era, al cabo, una baza política igual que había otras. Pero sería arbitrario desdeñar la posibilidad de que tanto unos como otros -algunos príncipes y algunos obispos de Roma- se preocuparan realmente por la salus animarum y llegaran a la paradójica conclusión de que se aseguraba mejor por medio de ese tipo de derechos.

En realidad, no se comprende de otra forma la subsistencia de esos regímenes durante siglos. Vale que hubiese sucesores de Pedro que, por debilidad o lo que fuere, cedieran ante tal o cual príncipe laico. Pero es inverosímil que no hubiese ninguno con las agallas necesarias para acabar con una forma como aquélla de injerencia laica en su potestad. Más bien hay que pensar en la posibilidad de que no lo considerasen injerencia, sino la manera de asegurar que las cosas funcionaran mejor.

¿Funcionaban mal? Aquí surge el problema del lenguaje, que es, simplemente, histórico -tan histórico como todo lo demás- y, por lo mismo, cambia (cambian no sólo las palabras, sino las acepciones y el alcance de los conceptos). No podemos asegurar que funcionase tan mal -por lo menos, en términos cuantitativos- como aseguraban los informantes de las autoridades civiles españolas. Pero es difícil poner en duda que -«cualitativamente»- lo que denunciaban sucedía en verdad. En la Dataría romana, se las ingeniaban para sacar el mayor provecho económico de los candidatos a beneficios de provisión directamente pontificia. Las triquiñuelas se describen en el libro de Barrio y arrojan una imagen vergonzosa, que hace pensar que Trento no acabó con la inmoralidad curial que indujo a Lutero a rasgarse las vestiduras y, de paso, disentir en lo doctrinal. Sería prolijo -aunque valdría la pena- detallar lo que se detalla en el libro. Se sumaban «gajes» que encarecían las bulas, se obligaba a los candidatos a luchar para conseguir un beneficio cada vez más rentable (y, con ello, otras tantas bulas y los dispendios consiguientes); se imponían «pensiones» a los que los lograban, con las cuales se mantenía a otro eclesiástico, italiano generalmente; para esto último -que iba contra las leyes españolas- se buscaban testaferros hispanos (que los había por lo tanto).

La imagen no es, la verdad, la una Iglesia «reformada» y tridentina.

Se entiende, en suma, de otra forma el hecho de que, encargados los reyes de Castilla de cristianar las «Indias» del otro lado del Atlántico (y, luego, del Pacífico), Carlos V lograse, a principios del siglo XVI, que el obispo de Roma le concediera el patronato universal sobre los beneficios indianos. Sólo él -el 
rey de las Españas- estaba en condiciones de recabar informes fidedignos para elegir al candidato mejor (cierto que -también- al que le interesara más por otros motivos). En Roma, no podía atinarse ni con lo uno ni con lo otro. Y el comportamiento de la Dataría apostólica -que acabamos de ver- con las «reservas pontificias» de beneficios de la España europea no era precisamente una razón que abogara por arriesgarse a que fueran ellos quienes asignaran los oficios y las rentas anejas de las iglesias americanas y asiáticas.

$$
* * *
$$

Visto así, el afán que se desató en Propaganda Fide, en la segunda mitad del Seiscientos, por informarse de la situación misionera de América y las autorizaciones que se concedieron, en la misma Congregación, para que nuevos religiosos cruzaran el Atlántico sólo podían suscitar recelo -como en efecto suscitaron- entre los españoles enterados de lo que sucedía con las «reservas pontificias» en la Dataría apostólica. El primero el rey, que era entonces Carlos II. El «Hechizado» era, en realidad, hombre de profundas convicciones cristianas y venía mostrando un sentido ético del gobierno que para sí quisieran los monarcas que los antecedieron y siguieron. Y ese celo se dejó ver especialmente en relación con los súbditos indianos potencialmente más débiles: los «indios», de una parte, y los esclavos, de otra*.

Dicho eso, hay ahora que referirse a lo contrario y comprender por qué no ha de medirse con el mismo rasero el ejercicio del Patronato Regio en los siglos XVI-XVII (al menos, en la monarquía española) con el del siglo XVIII, siendo como era, en una y otra época, la misma institución, mantenida por los monarcas sin solución de continuidad.

Y la razón estriba en que, al comenzar esa centuria, hubo una guerra de Sucesión y un cambio dinástico que abrió las puertas a la concepción absolutista francesa del ejercicio del poder regio; concepción absolutista que, en el siglo XVI, había llevado a su valedor principal -el católico Juan Bodino- a aconsejar al rey de Francia que se mantuviera todo lo distante que fuese posible de los asuntos religiosos y, en el siglo siguiente, otro católico -Bossuet- había argüido con la mismísima Biblia.

Es singular que, en los últimos años -muy últimos- parezca prestarse más atención a este último que a Bodino. Remito a los recientes estudios sobre su contribución a la retórica de la autoridad ${ }^{20}$ y acerca del calado de su filosofía personal. ${ }^{21}$

${ }^{20}$ Régent-Susini, Anne. 2011. Bossuet et la rhétorique de l'autorité, París, H. Champion: 838 págs.

${ }^{21}$ Bossuet philosophe: Actes de la journée d'étude, Sorbonne, 25 septembre 2010, organisé par l'assotiation Les amis de Bossuet el le Centre d'étude de la langue et de la littérature fraançaise des XVII et XVIII siècles, Meaux, Amis de Bossuet, 2011, 112 págs. 
Pues bien, la de Bossuet fue una de las respuestas posibles al problema que había dejado abierto Bodino al fundar su propuesta absolutista en el derecho común de tradición imperial romana, que, en su estadio final, había implicado una cierta deificación de la propia figura de los emperadores en términos que eran inadmisibles para un católico*. Su propuesta -la de Bodino- no tenía más fundamento, en realidad, que la que pudiera atribuirse a la propia tradición imperial romana (que, ciertamente, era muy grande). Pero Bodino -a juzgar por le notabilísimo alcance de su conocimiento del derecho romano de tradición imperialno podía desconocer la existencia de una tradición -tan rancia, tan romana y tan jurídica como aquella- que abocaba el derecho común al derecho de la ciudad (Roma en su caso) y, consecuentemente, a los derechos de los ciudadanos.

El silencio absoluto que mantuvo en sus obras en relación con esa otra tradición del ius commune -la del derecho romano de ciudad (o de ciudadanos)- y con las reelaboraciones sistemáticas que habían comenzado a realizar -y seguirían durante todo el siglo- Francisco de Vitoria y sus discípulos ponía de manifiesto que su propuesta era tan útil como fue, pero que carecía de un fundamento apto para quienes reflexionaban en su propio tiempo conforme a la más estricta lógica aristotélica.

Y Bossuet puso el remedio a esa falta de fundamento lógico (acaso el único argumento que podía justificar el silencio -si no el rechazo- de Bodino de la teoría política a que habían llegado esos otros católicos que se ajustaban con el mayor rigor a aquella lógica): el argumento de autoridad -por encima de cualquier otra autoridad- que era la Biblia (y que, para el caso de Francia) tenía la ventaja de coincidir totalmente con los afanes de Bodino: podían aceptarla tanto los protestantes como los propios católicos.

Solo que a un Príncipe imbuido en la idea de que su autoridad venía de Dios directamente era difícil convencerle de que la autoridad del Sumo Sacerdote de los relatos bíblicos - mutatis mutandis, el obispo de Roma- fuese superior a la suya.

Dicho de otra manera, los planteamientos de Bodino y Bossuet servirían de fundamento para la ancha corriente de teóricos católicos que, en el XVIII, reducían el poder de los papas a lo que se solía llamar «el fuero de la conciencia» y, en consecuencia, daban un fundamento como jamás había tenido a todo regio patronato.

Ya no era cosa de que el príncipe respectivo pudiera asegurarse de que ponía a buen recaudo, de cualquier abuso curial, los beneficios eclesiásticos, sino que se trataba de que, en Roma, reconociesen su autoridad omnímoda -la del príncipe- y se ajustaran a los límites de la del obispo de Roma (que era el fuero de la conciencia).

Se servían, en realidad, de otro hecho primordial, que era la propia indefinición de la doctrina de la Iglesia sobre la autoridad de los papas, y no porque du- 
dasen de su alcance, sino porque eran ellos los primeros que guardaban silencio sobre las conclusiones a que habían llegado aquellos teóricos católicos del siglo XVI que sistematizaron el derecho común de la ciudad de acuerdo con la lógica aristotélica; habían llegado a concluir -como contrapartida de los límites de la autoridad de los príncipes- que la temporal de los papas era sólo indirecta y, por lo tanto, no se podía mantener la viejísima idea del poder absoluto -sin distinciones entre lo eclesiástico y lo civil- de los pontífices romanos. Y a duras penas puede concluirse que fue León XIII el primer papa que asumió esa doctrina, cuando languidecía el siglo XIX. Ni más ni menos.

El enfrentamiento de doctrinas distintas -el cesaropapismo frente al absolutismo papal, y éste frente al liberalismo que empezaba a cuajar en el deseo de contar con «constituciones» escritas-y la indefinición del magisterio pontificio en esos puntos está en la base de la implicación de tantos católicos en la revolución francesa de 1789, en el pactismo neoescolástico que reapareció entonces en Francia en los escritos del clérigo Sieyès -por rudimentario que fuese-, la fosa enorme que se abrió en la América hispana -entre católicos- tras la invasión francesa de 1808; en fin, la íntima relación que aún se percibe entre la eclesiología de los príncipes absolutistas católicos despojados o arrojados del trono respectivo por la correspondiente revolución liberal y la convicción de los propios liberales de que al nuevo orden político le correspondía el derecho de patronato sobre los beneficios eclesiásticos con el mayor alcance que habían pretendido y, a veces, conseguido los príncipes derrocados.

Y ya se ve que todo eso -siendo la misma historia- es otra historia.

$$
\text { *** } *
$$

Recordemos ahora que Mateo Ricci fue a China por la vía portuguesa y sobre la base, por tanto, del reconocimiento del obispo de Roma al rey de Portugal -también- del Regio Patronato y con la particularidad insoslayable de que lo hizo en el período en que el rey de España lo era de Portugal, Castilla y Aragón y, en consecuencia, el pleito de los «ritos chinos» se dirimió -al principioen casa y su aspecto político tuvo, por eso mismo, una facies más complicada de lo que ahora se cree (entre aquellos que ven la discusión sobre los ritos chinos como un contraste entre la concepción misional itálica frente a la concepción española)..$^{22}$

No fue así y por eso decíamos -sine ira et cum studio- que la historia de Propaganda Fide puede devenir en ideología si nos descuidamos un tanto. Vale la pena detenerse en estudios como los reunidos en las actas del Congreso internacional «Los colegios apostólicos de Propaganda Fide: Historia y leyenda

22 El marco real se acerca más al que describe Valladares, Rafael. 2001. Castilla y Portugal en Asia (1580-168): Declive imperial y adaptación, Lovaina, Leuven University Press: XII + 143 págs. 
que se celebró en Zacatecas en 2004. No es cosa de atribuir a sus participantes lo que corre de nuestra cuenta, como lector -eso sí- de sus páginas y otras más. Pero resulta peregrino que se diga -como se dice en medios (hoy) de Propaganda Fide que la creación de este instituto supuso una reorientación «inculturadora» de la misión ad gentes y que se abandonó el empeño (que no existió jamás) de enseñar el catolicismo en castellano. Por ese camino, acabaríamos por ver Propaganda Fide como ideología. Y no fue eso. La labor de sus gentes en el Este de Europa y en pleno siglo XVII -que es del hablamos ahora- merece la mayor consideración; su presencia en la América de habla hispana, iniciada también entonces, fue labor... de españoles, claro es que con muchas excepciones. ${ }^{23}$

Ahora sabemos, además, que las irregularidades romanas en la colación de los oficios y de los beneficios acabaría por proyectarse asimismo sobre China, como se ve en las instrucciones que se daban en la institución romana en pleno siglo XVIII y ha estudiado Dong Hun Jang. ${ }^{24}$

Pero, ternes -y acaso con razón-, se volvería -desde la ya Congregaciónsobre los ritos chinos nada menos que en $1940 . .^{25}$

$$
\text { *** }
$$

Los contrastes del catolicismo español -y su facies de Monarquía- tenían desde luego otros aspectos no menos importantes en relación con la política. Y no sólo en América y en China. La obra coordinada por Heinz-Gerhard Haupt y Dieter Langewiesche sobre Nación y religión en Europea: Sociedades multiconfesionales en los siglos XIX y XX incumple -por fortuna- lo que ofrece en el título y no tan sólo se remonta a siglos anteriores, sino que se refiere a países cuyo carácter multiconfesional no era mayor que el de España (del que, como contrapartida, no se habla en el libro, ni aun en su traducción española. ${ }^{26}$ )

De eso -y, en concreto, de Bélgica- querría ocuparme por último.

La abrumadora mayoría que iba a tener en Bélgica el catolicismo hasta el día de hoy y la casi unanimidad que tuvo hasta 1800 no pueden desligarse de lo que se ha dicho antes - precisamente- sobre España. Fue el gobierno de los Habsburgo hispanos el que impidió, en el siglo XVI, la disidencia religiosa que

${ }^{23}$ Se desprende de las actas que acabo de citar, y ello a pesar de que no fue intención de los participantes. Se recogieron en 2008. Los Colegios Apostólicos de Propaganda Fide: Historia y leyenda: Memoria del Congreso, Guadalupe Zacatecas 27, 28 y 29 de enero de 2004, coord. y ed. por José Francisco Román Gutiérrez, Leticia Ivonne del Río Hernández y Alberto Carrillo Cázares, Zacatecas, Gobierno del Estado de Zacatecas: 491 págs.

${ }^{24}$ Dong Hun Jang. 2009. Stefano Borgia (1731-1804) e il clero autoctono: Gli orientamenti di Propaganda Fide sul clero autoctono in Cina nel XVII secolo, Roma, s.i.: 109 págs.

${ }^{25}$ D’Elia, Pasquale. 1940. «La recente istruzione della S.C. di Propaganda Fide sui riti cinesi»: $L a$ Civiltà Cattolica: 29 págs.

${ }^{26}$ Zaragoza, Institución Fernando el Católico, 2010, 417 págs. 
pudiera haber germinado en Bélgica y, con ello, paradójicamente, puso las bases para que la «confesionalización de la nación» belga en el siglo XIX -si fue entonces cuando se dio- se fuera perfilando en contraste con lo español... que, sin embargo, también era católico. La paradoja se advierte claramente en las páginas de ese libro que firma Johannes Kol.27

Iban a ser, en suma, dos «catolicismos» en liza o -por lo menos- en contraste. En realidad, hay que plantearse abiertamente si lo que estaba en liza no era sino el carácter «nacional» respectivo.

La denominación «nación española» tenía siglos de vitola. Pero, en pleno Seiscientos, nadie dudaba a la hora de hablar de los andaluces como de la «nación andaluza» ni de los súbditos de la corona aragonesa precisamente como «nación aragonesa», que, sin dejar de ser tal ni renunciar tampoco a formar parte de la «hispánica» o «española», albergaba en su seno unas cuantas «naciones» más: la catalana, la valenciana y otras. ${ }^{28}$

Lo que ahora habría que preguntarse es si se hablaba -en España y en Bélgica, en los siglos XVI y XVII- de «nación» (neerlandesa, pongo por caso) o de «naciones» (valona, flamenca etcétera). Según cuál sea la respuesta, podremos considerar - $\mathrm{O}$ no- que la «confesionalización de la nación belga» fue creación del siglo XIX o que, por el contrario, se había gestado con la Reforma, igual que casi todos los demás procesos europeos católicos o protestantes.

En España, y en pleno siglo XVII, nadie dudaba de que la palabra «nación» designaba, ante todo, parentesco -lazos de sangre- que, desde luego, implicaban cultura, aunque fuera tan solo porque suelen ser los progenitores de cada cual quienes inculcan en el recién nacido los hábitos que, de hecho, le permitirán convivir con otros, general y precisamente allí donde ha nacido (en la mayoría de los casos). En tal sentido, no termina uno de estar seguro de que «nación» y «patria» se emplearan como sinónimos en España, ${ }^{29}$ según podría desprenderse de lo que dice Rowe $\left.^{30}\right)$. Eran formas de «comunidad política», eso sí. ${ }^{31}$ Pero distintas. Al

\footnotetext{
${ }^{27}$ Koll, Johannes. 2010. «La Reforma controvertida: Nación y protestantismo en los católicos y liberales belgas del siglo XIX», Nación y religión en Europea: Sociedades multiconfesionales en los siglos XIX y XX, Haupt, Heinz-Gerhard y Langewiesche, Dieter (eds.): 119-156.

${ }^{28}$ Lo he documentado en varios estudios, que pueden consultarse desde www.joseandresgallego. com/contenido_01.htm.

${ }^{29}$ Gil Pujol, Xavier. 2005. «One king, one faith, many nations: Patria and nation in Spain, sixteenth-seveteenth centuries», «Patria» und «Patrioten» vor dem Patriotismus: Pflichten, Rechte, Glauben und die Rekonfigurierung europâischer Gemeinwesen im 17. Jahrhundert, Robert von Friedeburg (ed.), Wiesbaden, Harrassowitz Verlag: 105-138.

${ }^{30}$ Rowe. 2011: 12.

${ }^{31}$ A Thompson, A.A. 1995.«Castile, Spain, and the Monarchy: The political community from $p a-$ tria natural to patria nacional», en Spain, Europe, and the Atlantic World: Essays in honor of John H. Elliott, Richard L. Kagan y Geoffrey Parker, Eds.), Cambridge, Cambridge University Press: 125-159.
} 
menos, doy fe de ello en lo que atañe al siglo XVIII anterior a 1789.32 (De eso y de que la acepción se aplicaba también en Filipinas cuando se hablaba de la nación de los «sangleyes», que era el nombre que recibían los chinos).

Y así ocurrió hasta 1789, en que la revolución que estalló en Francia produjo -entre otras cosas- un cambio léxico y conceptual de enorme envergadura en todo el mundo occidental -y, luego, en todo el resto del planeta-, la primera de cuyas muestras fue la tendencia a reservar esa misma palabra -«revolución»para las convulsiones de gran envergadura, y no para un motín de tres al cuarto (por ejemplo). Los motines, hasta entonces, eran «revoluciones».33 Según se formó el mito de la «Revolución»-mito obediente al evidente peso de lo ocurrido en 1789-, los motines quedaron en «revueltas» o cosa parecida.

$$
\text { *** }
$$

Ahora fíjense lo que esto supone, y es que el hecho de que, en el siglo XIX, entre los belgas se invocara la «revolución» que hubo en Lieja muy pocos meses antes -semanas- de que estallase la Revolución francesa y que se presentara como prueba de que la «nación belga» encarnaba -cristianamente- la libertad (católica, aunque fuese frente a un obispo católico en ese caso) adquiere así mayor relieve que el que le otorga Koll. ${ }^{34}$ Aquella «revolución» fue, en rigor, un motín, que no habría que comparar-como se comparó más tarde- con la propia Revolución habida en Francia, sino -acaso- con los rebomboris del pa que tuvieron lugar en Cataluña en esos mismos meses de $1789^{35}$ y que -es curioso- no se recordarían luego para afirmar el carácter nacional de Cataluña, quizá porque ya había combustible bastante -y de la mejor calidad- en los sucesos de 1640 y la guerra dels segadors. ${ }^{36}$

En ese sentido, los disturbios ibéricos del entorno de 1640 -coetáneos de los que acabaron en la ruptura política de los Países Bajos- ya habían supuesto un cambio conceptual de primer orden, anterior al de 1789, del que no conozco un

${ }^{32}$ La imprescindible evidencia documental, en Andrés-Gallego, José. 2005. «Los tres conceptos de nación en el mundo hispano», Nación y constitución: De la Ilustración al liberalismo, Cinta Cantarela, (ed.) Sevilla, Junta de Andalucía, Universidad Pablo de Olavide y Sociedad Española de Estudios del Siglo: 123-146, y en 2008. «El uso de los conceptos patria y nación en el derecho indiano», Actas del XV Congreso del Instituto Internacional del Derecho Indiano: Córdoba (España), del 19 al 24 de septiembre de 2005, Manuel Torres Aguilar, (Coord.), Córdoba, Diputación y Universidad: 1313-1349, accesibles ambos en Internet.

33 Puse varios ejemplos en 1992. Quince revoluciones y algunas cosas más, Madrid, Ed. Mapfre, 350 , accesible también en Internet.

${ }^{34}$ Koll 2010: 124 y 138

${ }^{35}$ Sigue en pie el estudio de Castells Oliván, Irene. 1971. «Els rebomboris del pà de 1789 a Barcelona»: Recerques, 1: 51-81. También, Curet, Francesc. 1971 Rebomboris i bullangues de Barcelona, Barcelona, Bruguera: 2 volúmenes.

${ }^{36}$ Es muy útil, Simon i Tarrés, Antoni. 2003. Cròniques de la guerra dels segadors, Barcelona, Fundació Pere Coromines: 348 págs. 
caso parejo en el resto de Europa. Me refiero a que fue en esos días cuando se abandonó en Portugal la conciencia de formar parte de «España», cualquiera fuese su situación política -dependiente o independiente-; hasta entonces, hasta los días de mayor enfrentamiento con Castilla, la enemiga era ésta, pero ambas, parte de España. En adelante, el abandono de esa acepción es perceptible en la documentación portuguesa. A la vista de la obra de Rowe, me pregunto si no se gestaría en el propia Portugal durante las décadas anteriores -las de dominación de los reyes de Castilla-, en especial cuando Olivares se empeñó en conseguir que al rey de «las Españas» adornado de una larga enumeración de títulos de monarca entre los que se hallaban los de Castilla y Aragón, Navarra y, entonces, Portugal- se le llamara simplemente «rey de España» (Rowe: 81).

La política de Olivares debió calar entre los portugueses y -acaso- convencer a los que eran renuentes a aceptar la Unión de Armas -o querían, sencillamente, recuperar la independencia política- a asumir ahora la idea de que era, justamente, de «España» de la que tenían que separarse. Da que pensar en ello el hecho de que el debate entre teresianos y santiaguistas ganara también a los portugueses -claro es que a algunos- y discutiesen entre ellos y que participaran, además, en la parte que se centró en la duda de si Teresa era patrona de Castilla o lo era de toda España. ${ }^{37}$ No hay que olvidar que la decisión de que fuese patrona, la habían tomado, en 1627, las Cortes de Castilla, ${ }^{38}$ pocos meses después de que fuera canonizada santa Isabel de Portugal, la reina aragonesa. ${ }^{39}$ Para los portugueses de comienzos del siglo XVII, «España» era un concepto que les incluía a ellos desde mucho antes -siglos- de que se incorporasen a la corona de Castilla.

Uno echa de menos saber más de este asunto. La Unión de Armas de 1626 ha sido revaluada, en los últimos años, en Cataluña y Aragón ${ }^{40}$; querríamos saber sobre Portugal, en esa perspectiva de sentimientos «nacionales» de que hablamos ${ }^{41}$.

\footnotetext{
37 Rowe. 2010: 142.

38 Sobre la anulación de esa decisión por Urbano VIII -a favor, por tanto, de los santiaguistasRowe. 2011: 208.

39 Vid. la curiosa iconografía en Roselló Ramón y Bover, Jaime. 1981. Barroquisme processional a Mallorca: Les festes de la canonització de santa Elisabet de Portugal, 1626, Palma de Mallorca, Llebreria Jovellanos: 19 págs.

40 Vid. Belenguer Cebrià, Ernest. 1996. Cataluña: De la unión de coronas a la unión de armas (1479-1626), Madrid, Arco Libros: 84 págs., y Solano Camón, Enrique. 1987. Poder monárquico y estado pactista (1626-1652): Los aragoneses ante la Unión de Armas presentación de José Alcalá-Zamora y Queipo de Llano, prólogo de José A. Armillas Vicente, Zaragoza, Institución Fernando el Católico: 333 págs.

${ }^{41}$ Y no olvidamos, claro es, la obra de Schaub, Jean-Frédéric. 2001. Portugal na monarquia hispânica (1580-1640), Lisboa, Libros Horizonte: 112 pás.
} 